\title{
A Comparative Evaluation of Marginal Accuracy of Co- Cr Metal Copings Fabricated Using Traditional Casting Techniques and Metal Laser Sintering
}

\author{
Nitin Gautam ${ }^{1}$, Rajat R Khajuria ${ }^{2}$, Rimsha Ahmed ${ }^{3}$, Sunny Sharma ${ }^{4}$, Sarah Hasan ${ }^{5}$, Saad Hasan ${ }^{6}$
}

\begin{abstract}
Aims and objectives: The aim and objective of the study were to determine the amount of marginal discrepancy produced by cobalt-chromium (Co-Cr) copings fabricated using two different fabrication methods, i.e., traditional casting and direct metal laser-sintering (DMLS), and compare the values obtained between each fabrication technique and to evaluate if the fabrication technique can produce prosthesis that is within the standards of clinical acceptance of marginal discrepancy.

Materials and methods: Twenty metal copings each were fabricated by laser sintering and traditional casting method. The marginal gap at the buccal, lingual, mesial, and distal areas was measured using the silicone replica technique. The stereomicroscope and optical microscope were used to measure the marginal discrepancy between the working die and the copings. Statistical analysis was done using a $t$-test using Open-epi calculator software.

Results: The values indicate that the marginal gap was less for the copings fabricated using Co-Cr alloy crowns that were fabricated with direct metal laser-sintered technique than $\mathrm{Co}-\mathrm{Cr}$ alloy crowns fabricated with conventional casting technique.

Keywords: Conventional casting, Direct metal laser sintering, Marginal accuracy, Marginal fit, Metal coping.

International Journal of Clinical Pediatric Dentistry (2021): 10.5005/jp-journals-10005-1888
\end{abstract}

\section{INTRODUCTION}

In recent times, there has been a paradigm shift in restorative dentistry which may be attributed to the various technological advances in the discipline. One of the main factors for a successful prosthodontic treatment is to provide an accurately fitting restoration or prosthesis. In the case of fixed prosthodontics, the success of the prosthesis is mainly determined by the marginal gap and internal gap. ${ }^{1-5}$ Fabrication techniques like computer-aided milling and selective laser sintering, developed recently have gained a lot of popularity among commercial laboratories. However, despite these technological advances, the lost-wax technique still remains the most widely used technique for the fabrication of metal castings. The accuracy of fit of the casting is dependent on multiple factors starting from impression procedures till the final finishing of the prosthesis., ${ }^{6,7}$

Precious metal alloys have been used as the primary materials for dental restorations in the past but nowadays increase in the cost of such materials has encouraged the development of new dental alloys. Cobalt-chromium ( $\mathrm{Co}-\mathrm{Cr}$ ) alloys have been suggested as novel alternatives because of their high mechanical strength, corrosion resistance, biocompatibility, and cost efficiency. ${ }^{8-10}$

The purpose of this study is to evaluate and compare the marginal accuracy and internal fit of the conventionally cast Co-Cr alloy crowns with laser-sintered $\mathrm{Co}-\mathrm{Cr}$ alloy crowns using stereomicroscope and optical microscope and to assess the efficacy of these techniques to fabricate the crowns for fixed restorations.

\section{Materials and Methods}

Standardized stainless steel die with a cervical diameter of $13 \mathrm{~mm}$, $1.5 \mathrm{~mm}$ cervical margin, $5^{\circ}$ of uniform taper and height of $12 \mathrm{~mm}$,
1,3,4 Department of Prosthodontics and Crown and Bridge, Indira Gandhi Government Dental College and Hospital, Jammu, Jammu and Kashmir, India

${ }^{2}$ Department of Dentistry, Government Medical College, Doda, Jammu and Kashmir, India

${ }^{5}$ Department of Prosthodontics, Darbhanga Medical College and Hospital, Darbhanga, Bihar, India

${ }^{6}$ Department of Orthodontics, Mithila Minority Dental College and Hospital, Darbhanga, Bihar, India

Corresponding Author: Nitin Gautam, Department of Prosthodontics and Crown and Bridge, Indira Gandhi Government Dental College and Hospital, Jammu, Jammu and Kashmir, India, Phone: +919469214492, e-mail: nitingautam212@gmail.com

How to cite this article: Gautam N, Khajuria RR, Ahmed R, et al. A Comparative Evaluation of Marginal Accuracy of Co-Cr Metal Copings Fabricated Using Traditional Casting Techniques and Metal Laser Sintering. Int J Clin Pediatr Dent 2021;14(1):128-132.

Source of support: Nil

Conflict of interest: None

two retentive grooves ( $1 \mathrm{~mm}$ depth) extending $2 \mathrm{~mm}$ short of the finish line was prepared for the study.

A total of 40 specimens were prepared which included 20 samples of each category. All the samples prepared were of specific dimensions as a means for standardization.

The specimens were divided into two categories as follows: $(n=20)$

Group I: 20 Co-Cr crown specimens fabricated by conventional casting technique.

(0) Jaypee Brothers Medical Publishers. 2021 Open Access This article is distributed under the terms of the Creative Commons Attribution 4.0 International License (https://creativecommons.org/licenses/by-nc/4.0/), which permits unrestricted use, distribution, and non-commercial reproduction in any medium, provided you give appropriate credit to the original author(s) and the source, provide a link to the Creative Commons license, and indicate if changes were made. The Creative Commons Public Domain Dedication waiver (http://creativecommons.org/publicdomain/zero/1.0/) applies to the data made available in this article, unless otherwise stated. 


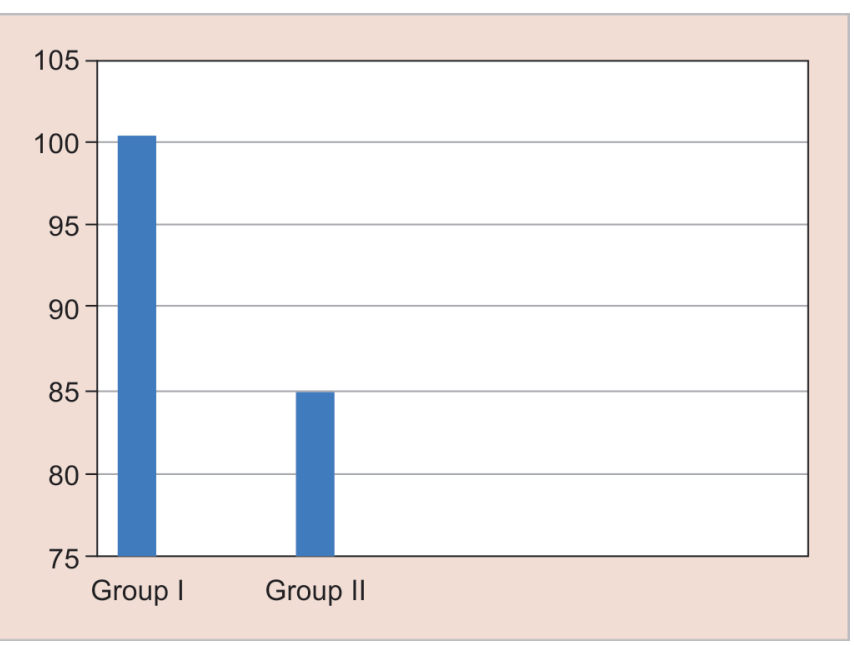

Fig. 1: Comparison between mean marginal discrepancy of group I and II

Group II: 20 Co-Cr crown specimens fabricated by direct metal laser-sintering (DMLS) technique.

The metal master die was cleaned with ethyl alcohol and distilled water and dried with a paper towel before making each impression. A metal impression tube with an inner diameter of 19 and $6 \mathrm{~mm}$ relief over the master die was fabricated for making impressions of the master die. The impression of the master die was made with polyvinyl siloxane impression material (Silagum DMG Germany). A two-step putty wash technique was used to make impressions of the master die. After impression procedures, all impressions were visually inspected for the reproduction of all surface details, as well as for the occurrence of any surface defect under magnification (Figs 1 and 2 and Tables 1 and 2).

High strength dental stone, type IV (Ultrarock Kalabhai Karson) was used to pour the impressions. To eliminate individual variability, the same operator poured a total of 40 impressions to make 40 working stone dies. The working stone dies were removed from the impressions after 1 hour and were randomly assigned identification numbers from 1 to 20 in each group and stored at room temperature.

\section{Fabrication of Group I Patterns}

Dental casting wax (S-U-Modelling wax, Schuler-Dental, Germany) was put in an electrical control wax bath and kept at the recommended temperature of $160^{\circ} \mathrm{F}$. The molten wax was poured initially into the sleeve to fill only in the cervical portion and then into assembly mold till the top edge of the die, later molten occlusal wax was poured slightly above the top edge of the sleeve.

\section{Fabrication of Group II Patterns and Crowns}

The dies were scanned using an optical scanner (3M Lava scan ST) to obtain a 3D model of the die on the computer. This 3D model on the computer was used to design the $\mathrm{Co}-\mathrm{Cr}$ crown using 3D modeling software. The software prepared the CAD model of the pattern. It was then exported to the Cambridge software to create slice (SLI format) files. These slice files were then exported to the MLS machine (EOS company). The machine built units by addition technique (Selective Laser Sintering), where each layer of $20 \mu \mathrm{m}$ $\mathrm{Co}-\mathrm{Cr}$ powder (Bego) was used to build the crowns. The powder particles are very fine ranging from 3 to $16 \mu \mathrm{m}$. Hence, 20 laser-

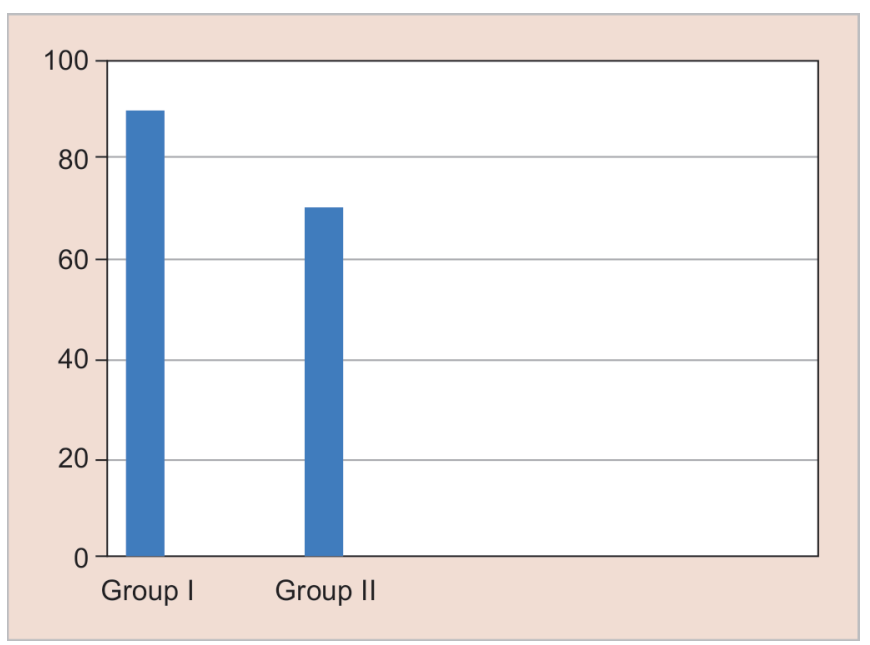

Fig. 2: Comparison between mean internal gap values of group I and II

Table 1: Comparison between mean marginal discrepancy of group I and II (in $\mu \mathrm{m})$

\begin{tabular}{lc}
\hline Groups & Mean marginal discrepancy \\
\hline Group I & $100.46 \pm 19.31$ \\
Group II & $84.82 \pm 16.94$ \\
\hline
\end{tabular}

Table 2: Comparison between mean internal gap values of group I and II (in $\mu \mathrm{m})$

\begin{tabular}{lc}
\hline Groups & Mean internal fit \\
\hline Group I & $89.71 \pm 27.76$ \\
Group II & $70.12 \pm 18.59$ \\
\hline
\end{tabular}

sintered crowns were obtained which were tagged with previously assigned numbers.

Spruing of group I wax patterns fabricated for conventional casting technique was done using sprue wax at the junction of the axial and occlusal surface. Investing was done using ringless casting system (Bego) investment material following the manufacturer's recommendations. The mold was kept for 30 minutes for the bench set. Burnout was done at $250^{\circ} \mathrm{C}$. All the castings were done in an induction casting machine (Galoni, Italy). Cobalt-chromium alloy (Bego) was used for the casting of the patterns. The castings were divested by manually breaking away the investment material as far as possible.

\section{Measurement of Marginal Discrepancy}

Each $\mathrm{Co}-\mathrm{Cr}$ crown obtained from the casting procedure, as well as metal laser sintering procedure, was seated on its respective working stone die and subjected to a constant load of $2 \mathrm{~kg}$ for 10 minutes. The marginal discrepancy between the working die and the copings was then measured with a stereomicroscope at a magnification of $40 \times$. Four pre-marked points $A, B, C$, and $D$ on working die were taken for measurement of marginal discrepancy. A jig was used to support the die and the crowns during measurements. The images were captured and later transformed to the computer; measurements were done with the help of the software. This study measured a perpendicular gap at $90^{\circ}$ representing the marginal gap. 


\section{Measurement of Internal Fit}

The crowns obtained were then cemented on their dedicated working dies using glass-ionomer cement and maintained under a constant load. The dies were then embedded in autopolymerizing acrylic resin for sectioning. The embedded crowns were then sectioned longitudinally using a slow-speed diamond cutting saw with a coolant to prevent distortion of metal during sectioning. The sections were oriented parallel to the axis of the microscope. Thus, the discrepancy was measured in microns. The discrepancy between the crowns and the die was measured at five different locations $E, F, G, H$, and I along the entire surface. The mean was calculated. These results were then subjected to statistical analysis.

\section{Results}

Grouping of samples and mean measurements of each specimen were as follows:

\section{Group I: Co-Cr Crowns Fabricated Using Conventional Casting Technique}

The mean marginal discrepancy of group I was found to be 103.73 $\mu \mathrm{m}$ with a standard deviation of 18.23 .

The mean internal gap value of group I was found to be 92.59 $\mu \mathrm{m}$ with a standard deviation of 31.6.

\section{Group II: Co-Cr Crowns Fabricated Using Laser Sintering Technique}

The mean marginal discrepancy of group II was found to be 88.74 $\mu \mathrm{m}$ with a standard deviation of 17.93 .

The mean internal gap value of group II was found to be 67.34 $\mu \mathrm{m}$ with a standard deviation of 17.92 .

After statistical analysis of both the groups, the results obtained were as follows:

The statistical comparison of marginal discrepancy of group I and group II showed a statistically significant difference $(p<0.05)$.

The statistical comparison of internal gap values of group I and group II showed a statistically significant difference $(p<0.05)$.

The result of the study showed that $\mathrm{Co}-\mathrm{Cr}$ alloy crowns fabricated with laser sintering technique (group II) showed a less mean marginal discrepancy of $92.59 \mu \mathrm{m}$ as compared to the Co$\mathrm{Cr}$ alloy crowns fabricated with conventional casting technique (group I) which showed a mean marginal discrepancy of $103.73 \mu \mathrm{m}$, which indicates that the marginal accuracy of $\mathrm{Co}-\mathrm{Cr}$ alloy crowns fabricated with laser sintering technique (group II) was significantly higher than Co-Cr alloy crowns fabricated with conventional casting technique (group I).

Similarly, the Co-Cr alloy crowns fabricated with laser sintering technique (group II) showed less mean internal gap value of $67.34 \mu \mathrm{m}$ as compared to the Co-Cr alloy crowns fabricated with conventional casting technique (group I) which showed a mean internal gap value of $88.74 \mu \mathrm{m}$. The values indicate that the lasersintered crowns showed a better fit as compared to conventionally casted crowns.

\section{Discussion}

The present study investigated the marginal accuracy and internal fit of $\mathrm{Co}-\mathrm{Cr}$ alloy crowns fabricated with conventional casting technique and DMLS technique.

The fabrication of a cast restoration involves a series of laboratory procedures that are technique sensitive. The procedures utilized are complex involving various stages, each of which may affect the dimensions and therefore, the accuracy of the final product. However, the marginal fit and accuracy of the patterns made go a long way in deciding the fit of the final restorations.

Base metal alloys, such as $\mathrm{Co}-\mathrm{Cr}$ and nickel-chromium ( $\mathrm{Ni}-\mathrm{Cr}$ ), have been widely used in the fabrication of fixed and removable partial denture frameworks since being introduced to dentistry in 1929. These alloys have increasingly replaced gold alloys owing to improved mechanical properties and decreased cost. ${ }^{11}$ Initially, gold alloys were selected because of their biocompatibility and ease of use. Due to an increase in gold prices substantially, less expensive alternatives like base metal alloys were used. However, the casting of base metal alloys is more technique sensitive compared to casting of noble alloys because of the high melting range and oxidation of base metal alloys during casting. In addition, due to their high hardness, grinding of cast base metal alloys to finish castings is time-consuming for dental laboratories. ${ }^{3}$ Cobalt-chromium alloys were preferred, the major advantages of this alloy are its lower thermal expansion coefficient and higher creeping strength in high temperatures during porcelain firing. ${ }^{12}$ Nevertheless, $\mathrm{Ni}-\mathrm{Cr}$ alloys despite their satisfactory clinical performance and high modulus of elasticity, give them rigidity even in small thickness, these alloys have limitations related to their high hardness, difficult laboratory processing ${ }^{13}$ and low flow rate, the high incidence of incomplete margins being the most frequently reported problem. According to Moffa et al., ${ }^{14}$ the increase of casting temperature increases the flow of the $\mathrm{Ni}-\mathrm{Cr}$ alloy and reduces casting failures; nevertheless, it also increases surface roughness, which poses additional difficulty to the finishing and polishing procedures. ${ }^{12}$ Many of the $\mathrm{Ni}-\mathrm{Cr}$ alloys contain beryllium, which can be toxic in uncontrolled dental laboratories.

Of various techniques for fixed prosthodontics, mainly, conventional lost-wax technique accelerated casting technique, CAD/CAM is being used nowadays. Two fabrication methods are primarily used with this new digitized technique, either by milling the frameworks from a block of Co-Cr or by using direct laser metal sintering (DLMS). Unlike the milling technique, DLMS sinters a metal powder in layers, which is then fused by laser welding. ${ }^{3}$ The newly developed DMLS system is an additive metal fabrication technology, based on information received from three dimensional CAD, in which metal powder is shot selectively using a data file and fused with a laser to laminate approximately a 20-60- $\mathrm{mm}$-thick layer with each shooting to complete a metal structure. There is little data on the marginal fit of fixed dental prostheses (FDPs) fabricated by the DMLS system so far. ${ }^{15}$ Hence, the present study was designed.

An improperly adapted margin of the metal casting causes plaque retention leading to periodontal diseases and secondary caries. ${ }^{16}$ To achieve a clinically acceptable result for FDPs the fit of the construction is one important requisite for a good longterm prognosis. A study performed by Foster ${ }^{17}$ on 142 failed FDPs concluded that one important reason for this technical complication was an unacceptable fit. An unacceptable marginal gap could result in cement washout with subsequent biological complications, such as secondary caries, periodontal problems, and pulpitis. ${ }^{18}$ Accurate marginal adaptation is necessary for maintaining gingival health and to protect the tooth from physical, chemical, bacterial, and thermal injuries. ${ }^{16}$ Several methods for measuring the marginal fit of dental prostheses have been used in previous studies: (1) a direct measuring method measures the gap or amount of cement directly by microscope after seating the dental prosthesis on the 
tooth model and incising it (2) using silicone replica, the thickness of silicone located between the dental prosthesis and tooth model is measured by microscope. Shortcomings of this technique might be the defects of the silicone material in the area of measurement and inaccuracies in the assessment of the film thickness with a microscope (3) a recently-introduced technique using X-ray microcomputed tomography (micro CT) that involves shooting the inner side of the dental prosthesis. ${ }^{15}$ The cross-sectional evaluation of margins allows greater precision in the determination of measuring points and permits the determination of the degree of horizontal discrepancy. ${ }^{19}$

For testing, a standardized complete crown preparation stainless steel die was made with a cervical diameter of $13 \mathrm{~mm}, 1.5$ $\mathrm{mm}$ cervical margin, $5^{\circ}$ of uniform taper and height of $12 \mathrm{~mm}$, two retentive grooves ( $1 \mathrm{~mm}$ depth) extending $1 \mathrm{~mm}$ short of the finish line in accordance with various studies reviewed. ${ }^{20,21}$ Impressions of the master die were made in addition to the silicone by two-stage putty wash technique The advantage of the two-step technique over the one-step impression technique is that it records the surface completely in light body impression material, ${ }^{22}$ which influences a better reproduction of surface topography. Impressions of the master die were then poured using type IV dental stone to obtain working dies.

In this study, total of two groups were made as follows: $(n=20)$ Group I: Co-Cr alloy crowns fabricated by a conventional casting technique.

Group II: Co-Cr alloy crowns fabricated by laser sintering technique.

Wax patterns for group I crowns were prepared on working die with casting wax by using bulk placement technique by a standardized method. Patterns and crowns for group II crowns were made by scanning the die and converting it into standard CAD format known as STL. This 3D model on the computer was used to design the pattern of the coping using the software (3 M Lava design 7). The software then prepared the CAD model of the pattern. It was then exported to the Cambridge software to create slice (SLI format) file exported slice files to MLS machine of EOS company. The machine then built units by addition technique with each layer of $20 \mu \mathrm{m}$. The $\mathrm{Co}-\mathrm{Cr}$ powder was used to build the crowns. So, the accuracy of patterns prepared by this technique depended upon many factors. First, it depended upon how accurately the die was scanned by the scanner. Second, it depended upon the operator who had designed the pattern in the software. Although the software located the margin by itself, it required modification by the operator. To avoid individual variability, the same operator designed all the patterns in this study.

For group I patterns, ringless casting technique was followed in this study. Lombardas et al. ${ }^{23}$ found in their study that the castings produced by the ringless casting technique provided less vertical margin discrepancy than the castings produced with the conventional metal ring technique. All the castings were done with Co-Cr base metal alloy.

After fabrication, each Co-Cr crown obtained from the casting procedure, as well as metal laser sintering procedure, was seated on its previously assigned respective working stone die and subjected to a constant load of $2 \mathrm{~kg}$ for 10 minutes. ${ }^{24}$ The marginal discrepancy between the working die and the copings was then measured with stereomicroscope. The crowns obtained were then cemented on their dedicated working dies using glass-ionomer cement. The dies were then embedded in autopolymerizing acrylic resin for sectioning. The embedded specimens were then sectioned longitudinally using a slow-speed diamond cutting saw with a coolant to prevent distortion of metal during sectioning. A similar method was used earlier for sectioning by Davis, ${ }^{25}$ Teteruck and Mumford. ${ }^{26}$ These sections were then measured under an optical microscope for evaluation of internal fit.

Holmes et al. ${ }^{27}$ have described absolute marginal discrepancy which they have defined as the angular combination of marginal discrepancy and any extension error (under-extension or overextension) or perhaps more simply described as the distance from the margin of casting to cavosurface angles of tooth preparation. They stated that this distance would always be the largest measurement of error at the margin and reflect the total crown misfit at that point, vertical and horizontal.

Ucar et al. ${ }^{3}$ in their study significantly higher mean (SD) lightbody silicone weights $(p<0.001)$ were observed in the laser-sintered Co-Cr alloy group [14.34 (1.67) $\mathrm{mg}$ ] compared to the conventionally cast $\mathrm{Ni}-\mathrm{Cr}$ alloy group [9.36 (1.97) $\mathrm{mg}$ ] and Co-Cr alloy group [7.85 (1.19) $\mathrm{mg}$. The mean value of internal fit of laser-sintered $\mathrm{Co}-\mathrm{Cr}$ group was $62.6 \mu \mathrm{m}$, and for conventionally casted $\mathrm{Co}-\mathrm{Cr}, \mathrm{Ni}-\mathrm{Cr}$ alloy group was $50.55,58.21 \mu \mathrm{m}$. Ortorp et al. ${ }^{18}$ reported the mean value of internal fit of direct metal laser-sintered crowns to be 69 and $99 \mu \mathrm{m}$ in premolar and molar region, respectively. The mean internal fit by the conventional lost-wax method was found to be $133 \mu \mathrm{m}$ reported that the best fit of three-unit FPD's based on the means in $\mu \mathrm{m}$ for all measurement points was in the DLMS group 84, followed by milled wax with lost-wax method (MW 117), conventional lost-wax method (LW) 133, and milled Co-Cr (MC) 166. Significant differences were present between milled $\mathrm{Co}-\mathrm{Cr}(\mathrm{MC})$ and DLMS $(p<0.05)$. The reduced number of steps of DMLS ${ }^{3,18}$ may contribute to explaining those findings. ${ }^{28}$ The values in the present study for the metal laser sintering group are in accordance with the above studies. Kim et al..$^{15}$ in their study found that the mean values of an absolute marginal discrepancy, marginal discrepancy, and internal gap were significantly larger in the three-unit FDPs fabricated using a newly developed DMLS system using $\mathrm{Co}-\mathrm{Cr}$ alloy than in three-unit FDPs fabricated by a conventional lost-wax technique (LW) using Ni-Cr alloy. The marginal fit of the DMLS system appeared significantly inferior compared to that of the conventional LW method and slightly larger than the acceptable range. The result is inconsistent with a previous investigation that has reported a superior fit of the DMLS system compared to the conventional method.

The CAD/CAM technique contains fewer production steps compared to the lost-wax technique, however, three main factors could affect the fit: the precision of the scanner that reads the abutments, how the software can transform the scanning data into a 3D model in the computer, and the precision of the machine that will CAM the objects from the CAD data. ${ }^{28}$ According to the manufacturer, the scanner has a precision of $20 \mu \mathrm{m}$. However, according to Persson et al. ${ }^{28}$ A scanner using laser technique tends to make sharp edges rounder. Possible explanations for this could be the optical properties of the plaster or the camera used..$^{18}$

Clinical implementation of the DMLS system seems to require further investigation because studies of restoration longevity are scarce. ${ }^{15}$

\section{Limitations of the Study}

- The stone dies were prepared using polyvinyl siloxane impression material and a die stone by two-step putty wash technique. Therefore, the resultant marginal discrepancy and 
fit is also due to polymerization shrinkage of the impression material and setting expansion of the die stone.

- The incorporation of errors during scanning of the die cannot be overlooked. More detailed analysis with a larger sample size needs to be done.

- The results of this study are based on an in vitro evaluation and hence further clinical studies are required to substantiate the results.

\section{CONCLUSION}

Within the limitations of this study, the following conclusions were drawn:

- The mean marginal discrepancy of Co-Cr alloy crowns fabricated with conventional casting technique was found to be more than the crowns fabricated with laser-sintered technique.

- The marginal accuracy of Co-Cr alloy crowns fabricated with the laser-sintered technique was significantly higher than $\mathrm{Co}-\mathrm{Cr}$ alloy crowns fabricated with conventional casting technique.

\section{References}

1. Fusayama T. Factors and technique of precision casting part I. J Prosthet Dent 1959;9(3):468-485. DOI: 10.1016/0022-3913(59) 90080-0.

2. Schwartz IS. A review of methods and techniques to improve the fit of cast restorations. J Prosthet Dent 1986;56(3):279-283. DOI: 10.1016/0022-3913(86)90003-x.

3. Ucar Y, Akova T, Akyil MS, et al. Internal fit evaluation of crowns prepared using a new dental crown fabrication technique: lasersintered Co-Cr crowns. J Prosthet Dent 2009;102(4):253-259. DOI: 10.1016/S0022-3913(09)60165-7.

4. Plekavich EJ, Joncas JM. The effect of impression-die systems on crown margins. J Prosthet Dent 1983;49(6):772-776. DOI: 10.1016/0022-3913(83)90346-3.

5. Grenade C, Malnjot A, Vanheusden A. Fit of single tooth zirconia copings: comparison between various manufacturing process. J Prosthet Dent 2011;105(4):249-255. DOI: 10.1016/S00223913(11)60040-1.

6. Taggart WH. A new and accurate method of making gold inlays. Dent Cosmos 1907;49:1117-1121.

7. Smith $C$, Twiggs $S$, Fairhurst $C$, et al. Determining the marginal discrepancy of cast complete crowns. J Prosthet Dent 1985;54(6):778784. DOI: 10.1016/0022-3913(85)90469-x.

8. Brecker SC. Porcelain baked to gold - a new medium in prosthodontics. J Prosthet Dent 1956;6(6):801-810. DOI: 10.1016/0022-3913(56) 90077-4.

9. Johnston JF, Dykema RW, Cunningham DM. The use and construction of gold crowns with a fused porcelain veneer- a progress report. J Prosthet Dent 1956;6(6):811-821. DOI: 10.1016/0022-3913(56) 90078-6.

10. Christensen GJ. Longevity of posterior tooth dental restorations. J Am Dent Assoc 2005;136(2):201-203. DOI: 10.14219/jada. archive.2005.0142.

11. Bezzon $\mathrm{O}$, Pedrazzi $\mathrm{H}$, Zaniquelli $\mathrm{O}$, et al. Effect of casting technique on surface roughness and consequent mass loss after polishing of $\mathrm{NiCr}$ and $\mathrm{CoCr}$ base metal alloys: a comparative study with titanium. J Prosthet Dent 2004;92(3):274-277. DOI: 10.1016/j. prosdent.2004.04.021.

12. Adriana Da FPC, Ricardo FR, Maria DG, et al. Evaluation of the castability of a Co-Cr-Mo-W alloy varying the investing technique. Braz Dent J 2005;16(1):50-55. DOI: 10.1590/S0103-64402005000100009.

13. Weiss PA. New design parameters: utilizing the properties of nickelchomium superalloys. Dent Clin North Am 1977;21(4):769-785.

14. Moffa JP, Lugassy AA, Guckes AD, et al. An evaluation of nonprecious alloys for use with porcelain veneers. Part I. Physical properties. J Prosthet Dent 1973;30(4 Pt 1):424-431. DOI: 10.1016/00223913(73)90164-9.

15. Kim K-B, Kim W-C, Kim H-Y, et al. An evaluation of marginal fit of three-unit fixed dental prostheses fabricated by direct metal laser sintering system. Dent Mater 2013;29(7):91-96. DOI: 10.1016/j. dental.2013.04.007.

16. Felton DA, Kanoy BE, Bayne SC, et al. Effect of in vivo crown margin discrepancies on periodontal health. J Prosthet Dent 1991;65(3):357364. DOI: 10.1016/0022-3913(91)90225-I.

17. Foster LV. Failed conventional bridge work from general dental practice: clinical aspects and treatment needs of 142 cases. Br Dent J 1990;168(5):199-201. DOI: 10.1038/sj.bdj.4807133.

18. Ortorp A, Jonsson D, Mouhsen A, et al. The fit of cobalt-chromium three-unit fixed dental prostheses fabricated with four different techniques: a comparative in vitro study. Dent Mater 2011;27(4):356363. DOI: 10.1016/j.dental.2010.11.015.

19. Sorenson JA. A standardized method for determination of crown margin fidelity. J Prosthet Dent 1990;64(1):18-24. DOI: 10.1016/00223913(90)90147-5.

20. Millar BJ, Dunne SM, Robinson PB. In vitro study of the number of surface defects in monophase and two-phase addition silicone impressions. J Prosthet Dent 1998;80(1):32-35. DOI: 10.1016/s00223913(98)70088-5.

21. Hung SH, Purk JH, Tira DE, et al. Accuracy of one-step versus two step putty wash addition silicone impression technique. J Prosthet Dent 1992;67(5):583-589. DOI: 10.1016/0022-3913(92)90151-y.

22. Capuli S, Varvara G. Dimensional accuracy of resultant casts made by a monophase, one-step and two-step, and a novel two-step putty/ light-body impression technique: an in vitro study. J Prosthet Dent 2008;99(4):274-281. DOI: 10.1016/S0022-3913(08)60061-X.

23. Lombardas P, Carbunaru A, Mcalarney ME, et al. Dimensional accuracy of castings produced with ringless and metal ring investment systems. J Prosthet Dent 2000;84(1):27-31. DOI: 10.1067/ mpr.2000.107783.

24. Konstantoulakis E, Nakajima H, Woody RD, et al. Marginal fit and surface roughness of crowns made with an accelerated casting technique. J Prosthet Dent 1998;80(3):337-345. DOI: 10.1016/s00223913(98)70135-0.

25. Davis DR. Limiting wax pattern distortion caused by setting expansion. J Prosthet Dent 1987;58(2):229-234. DOI: 10.1016/00223913(87)90182-x.

26. Teteruck WR, Mumford G. The fit of certain dental casting alloys using different investing materials and techniques. J Prosthet Dent 1966;16(5):910-927. DOI: 10.1016/0022-3913(66)90014-x.

27. Holmes JR, Bayne SC, Holland GA, et al. Considerations in measurement of marginal fit. J Prosthet Dent 1989;62(4):405-408. DOI: 10.1016/0022-3913(89)90170-4.

28. Persson A, Andersson M, Oden A, et al. A three dimensional evaluation of a laser scanner and a touch-probe scanner. J Prosthet Dent 2006;95(3):194-200. DOI: 10.1016/j.prosdent.2006.01.003. 